\title{
Intelligent analysis for medical multi-modal data
}

Published online: 16 January 2021

(C) Springer Science+Business Media, LLC, part of Springer Nature 2021

Multimedia Tools and Applications gratefully acknowledges the editorial work of the scholars listed below on the special issue entitled "Intelligent Analysis for Medical Multi-Modal Data" (SI 1170).

Of 22 papers submitted to this issue, 8 were eventually accepted after a stringent peer review process.

\section{Corresponding Guest Editor}

\section{Shihui Ying}

Shanghai University, China

Email: shying@shu.edu.cn

\section{Guest Editors}

\section{Yang Wu}

Kyoto University, Japan

Email: wu.yang.8c@kyoto-u.ac.jp

\section{Xiaofeng Zhu}

Massey University, New Zealand

Email: s.zhu@massey.ac.nz

Publisher's note Springer Nature remains neutral with regard to jurisdictional claims in published maps and institutional affiliations. 